\title{
OPTIMAL DESIGN OF INTERGOVERNMENTAL GRANTS UNDER ASYMMETRIC INFORMATION
}

\author{
BERND HUBER \\ MARCO RUNKEL
}

CESIFo Working PAPER No. 919

CATEgORY 1: Public FinANCE

APRIL 2003

An electronic version of the paper may be downloaded

- from the SSRN website: Www.SSRN.com

- from the CESifo website: www.CESifo.de 


\title{
OPTIMAL DESIGN OF INTERGOVERNMENTAL GRANTS UNDER ASYMMETRIC INFORMATION
}

\begin{abstract}
This paper develops a theoretical explanation why it may be optimal for higher-level governments to pay categorical block grants or closed-ended matching grants to local governments. We consider a federation with two types of local governments which differ in the cost of providing public goods. The federal government redistributes between jurisdictions, but cannot observe the type of a jurisdiction. In this asymmetric information setting it is shown that the second-best optimum can be decentralized with the help of categorical block grants and closed-ended matching grants, but not with unconditional block grants or open-ended matching grants.
\end{abstract}

JEL Code: H77, D82.

Keywords: asymmetric information, categorical block grants, closed-ended matching grants.

Bernd Huber

Department of Economics

University of Munich

Ludwigstr. 28,

80539 Munich

Germany

huber.office@lrz.uni-muenchen.de
Marco Runkel

Department of Economics

University of Munich

Ludwigstr. 28,

80539 Munich

Germany

runkel@lrz.uni-muenchen.de 


\section{Introduction}

In the literature on fiscal federalism, the optimal design of intergovernmental grants has extensively been analyzed. For a survey see e.g. Oates $(1972,1999)$ and Wildasin (1986). The key results of this literature can be summarized as follows: If a higher-level government pays grants to lower level governments, efficiency considerations imply that the grants should be designed as unconditional block grants. The lump-sum character of this type of transfers ensures that the spending decisions of lower level governments are not distorted. However, distortionary grant policies may be optimal if local and regional decisions induce inefficiencies. One important example are externalities between regions arising, for example, if a region provides public goods which also benefit residents of other regions. The most straightforward way to internalize such externalities is an open-ended matching grant which subsidizes the cost of the public good producing the external benefits.

One puzzling fact is that the theoretical predictions of the fiscal federalism literature are hardly consistent with many observed grant policies. As pointed out by Oates (1999), the standard theory leaves little room to explain the existence of categorical block grants, i.e. lump-sum grants which have to be spent on certain purposes, and closed-ended matching grants, i.e. matching grants where a ceiling on the total amount of grants is imposed. These two types of grants are usually distortionary and not well suited to internalize externalities (e.g. Bezdeck and Jonathan 1988). But in many federations, they form a key part of federal and regional grants policy. The most striking example is the U.S. system of federal grants to state and local governments. The design features of these grants are summarized in Table 1. The number of non-matching (block) grants and matching grants is roughly equal. Nearly all grants are categorical and closed-ended such that most of the non-matching grants represent categorical block grants and most of the matching grants are closed-ended. Similar evidence is obtained if we look at the volume of the transfers. Further examples of categorical block grants and closed-ended matching grants can be found in the Structural Fund and the Cohesion Fund of the European Union (e.g. Hevré 2002) and in the federal systems of Canada (Baker et al. 1999) and Germany (Huber et al. 2002).

In this paper, we develop a theoretical explanation why it may be optimal for higher- 
Table 1: Design Features of U.S. Federal Grants, Fiscal Year 1994

\begin{tabular}{cccccc}
\hline & \multicolumn{2}{c}{ Grants with each feature } & & \multicolumn{2}{c}{ Obligations } \\
\cline { 2 - 3 } \cline { 5 - 6 } Grant design feature & Number & Percent & & Dollars in Billion & Percent \\
\hline Non-matching & 318 & 50.2 & & 67.5 & 31.5 \\
Matching & 315 & 48.2 & & 146.6 & 68.5 \\
\hline Broad-purpose & 16 & 2.5 & & 52.9 & 24.7 \\
Categorical & 617 & 97.5 & & 161.2 & 75.3 \\
\hline Open-ended & 16 & 2.5 & & 105.1 & 49.1 \\
Closed-ended & 617 & 97.5 & & 109.0 & 50.9 \\
\hline Total & $\mathbf{6 3 3}$ & $\mathbf{1 0 0 . 0}$ & & $\mathbf{2 1 4 . 1}$ & $\mathbf{1 0 0 . 0}$ \\
\hline
\end{tabular}

Source: U.S. General Accounting Office (1996, p. 16)

level governments to pay categorical block grants and closed-ended matching grants. We consider a federation with two types of local or regional governments (jurisdictions). Both types of jurisdictions provide two local public goods, but differ in the cost of producing one of these goods. The objective of the federal government (the center) is to optimally redistribute from (richer) low-cost to (poorer) high-cost regions. However, the federal government cannot directly observe whether a jurisdiction is of the high-cost or the low-cost type. In this asymmetric information setting, we derive the secondbest optimum in a centralized economy where both transfer and spending decisions are made at the federal level. We then show that the second-best optimum can be achieved as the outcome of decentralized spending decisions if the federal government (i) imposes a lump-sum tax on low-cost jurisdictions and (ii) offers a combination of an unconditional block grant and a categorical block grant or a closed-ended matching grant to high-cost regions. Pure unconditional block grants or open-ended matching grants are not suitable to implement the second-best allocation. The key rationale of these results is that the second-best optimum is characterized by a distortion of the spending decision of high-cost jurisdictions and a self-selection constraint which makes it unattractive for low-cost jurisdictions to mimic high-cost ones. At least one of these two conditions is violated if the center employs open-ended matching grants or pure unconditional block grants, but using categorical block grants or open-ended matching grants allows the federal government to satisfy both conditions simultaneously. 
In recent years, there is a growing literature on fiscal federalism under asymmetric information, for example, Cremer et al. (1996), Bucovetsky et al. (1998), Lookwood (1999), Cornes and Silva (2000, 2002a, 2003) and Bordignon et al. (2001). However, since all these studies include in their analysis one public good only, they cannot explain the use of categorical block grants, and they also do not make the point for closed-ended matching grants. Cornes and Silva (2003) consider the spending mix on two public goods under asymmetric information. But they also do not derive an explanation for categorical block grants, since they assume that the federal government can condition its transfers on total expenditures of a jurisdiction only. In contrast, we focus on the case where the federal government can observe the expenditures on each of the two public goods and, thus, conditions grants on these expenditures. However, the federal government cannot directly infer the production cost and the quantity of public goods. This assumption reflects the idea that budgetary expenditures are often easily observed, while the central government has little information about the cost structure and the quantity or quality of regional public good supply. This view is also supported by the many existing grant programs which, like the above-mentioned U.S. federal grants system, are conditioned upon actual budgetary expenditures.

The paper is organized as follows. In section 2, we describe the basic structure of the model. Section 3 provides an analysis of optimal redistribution under perfect information which serves as benchmark for the discussion of the second-best optimum under asymmetric information in section 4. In section 5, we then analyze the role of different grant types in decentralizing the second-best optimum. Section 6 concludes.

\section{Model}

Consider a federation consisting of a federal government (the center) and $n>1$ regional or local governments (jurisdictions). Each jurisdiction provides two different local public goods, good $F$ and good $G$. In providing good $F$, jurisdictions face the same cost while they differ with respect to the cost of good $G$. We distinguish two types of jurisdictions: a low-cost type denoted by the index $\ell$ and a high-cost type denoted by the index $h$. The number of low-cost and high-cost jurisdictions is equal to $n_{\ell} \geq 1$ and $n_{h} \geq 1$, respectively, with $n_{\ell}+n_{h}=n$. 
The public good $F$ serves as numeraire. Hence, we denote by $f_{i}$ the quantity as well as the cost of good $F$ provided by a jurisdiction of type $i \in\{\ell, h\}$. With respect to good $G$, total cost of a type $i$ jurisdiction amounts to

$$
e_{i}=g_{i}+\theta_{i}
$$

where $g_{i}$ denotes the quantity of good $G$ and $\theta_{i}$ is a cost parameter which can be interpreted, for example, as fixed or start-up cost of producing good $G$. The cost parameter differs across jurisdictions, and we assume $\theta_{h}>\theta_{\ell}$ so that for any given quantity of good $G$ a type $h$ jurisdiction incurs higher cost than a type $\ell$ jurisdiction. ${ }^{1}$

The budget constraint of a type $i$ jurisdiction is given by

$$
f_{i}+e_{i}=t+\tau_{i}
$$

Equation (2) requires that total expenditures on the two public goods must equal a jurisdiction's revenues. Local revenues stem from two sources. First, each jurisdiction collects local tax revenues $t$ which are assumed to be exogenously given and independent of the jurisdiction's type. Second, each jurisdiction of type $i$ receives a transfer $\tau_{i}$ from the federal government. $\tau_{i}$ is not restricted in sign. If it is negative, it represents a tax which the center imposes on a type $i$ jurisdiction.

Each jurisdiction is populated by a representative household. Households are identical across jurisdictions. Since tax revenues are exogenously given in our model, we entirely ignore private consumption in the following discussion. ${ }^{2}$ Utility of the representative household in a jurisdiction can therefore be expressed as a function of the quantities of the two public goods. As in much of the literature on fiscal federalism, we assume that utility is additively separable. More formally, utility of the household in a region of type $i$ takes the form

$$
u_{i}=U\left(f_{i}\right)+V\left(g_{i}\right)
$$

with $U^{\prime}, V^{\prime}>0$ and $U^{\prime \prime}, V^{\prime \prime}<0$. The form of the utility function (3) ensures that none of the public goods is inferior (e.g. Deaton and Muellbauer 1980, p. 139).

\footnotetext{
${ }^{1}$ Cost differences among jurisdictions can also be modeled as differences in unit cost instead of differences in fixed cost (e.g. Cornes and Silva 2003). In footnote 3, we discuss the consequences of this assumption for our results in more detail.

${ }^{2}$ None of our results is affected if we extend our model by introducing private consumption choices.
} 
Consider finally the federal government. In our model, the role of the federal government is to redistribute among regions. The federal budget constraint is given by

$$
n_{\ell} \tau_{\ell}+n_{h} \tau_{h}=0
$$

(4) implies that the federal government collects revenues from one type of jurisdictions in order to finance transfers to the other type.

\section{Full Information Allocation}

As a benchmark, we first consider the case of full information. In this case, the federal government can observe both the costs and the quantities of local public goods. Therefore, by equation (1) the center can also verify whether the jurisdiction is of the high-cost or low-cost type. In what follows, we will first characterize the optimal allocation if the federal government directly chooses all variables (centralization). Since we ignore other distortions resulting, for example, from taxation, the full information allocation is also denoted as first-best. At the end of this section, we will discuss how this first-best allocation can be decentralized.

The objective of the federal government is to maximize total welfare of all jurisdictions subject to its budget constraint (4). Using (1) and (2), this welfare maximization of the center may be written as

$$
\max _{e_{\ell}, e_{h}, \tau_{\ell}, \tau_{h}} \sum_{i \in\{\ell, h\}} n_{i}\left[U\left(t+\tau_{i}-e_{i}\right)+V\left(e_{i}-\theta_{i}\right)\right] \quad \text { s.t. }
$$

Denote the solution to (5) by the superscript 'o'. Then, the FOCs for the first-best optimum can be rearranged to yield

$$
\frac{U^{\prime}\left(f_{\ell}^{o}\right)}{V^{\prime}\left(g_{\ell}^{o}\right)}=\frac{U^{\prime}\left(f_{h}^{o}\right)}{V^{\prime}\left(g_{h}^{o}\right)}=1
$$

and

$$
V^{\prime}\left(g_{\ell}^{o}\right)=V^{\prime}\left(g_{h}^{o}\right)
$$

Equation (6) requires as a standard efficiency condition that in both types of regions the marginal rate of substitution between the two public goods is equal to the marginal rate 
of transformation which equals unity. Equation (7) reflects the distributional objective of the federal government. It implies that, at the optimum, the marginal utility of $\operatorname{good} G($ and of good $F$ ) is equalized across jurisdictions. The optimum conditions (6) and (7) are used in appendix A to prove

Proposition 1 The optimal allocation under full information satisfies

$$
\begin{aligned}
& g_{\ell}^{o}=g_{h}^{o}, \quad f_{\ell}^{o}=f_{h}^{o}, \quad e_{\ell}^{o}=e_{h}^{o}-\left(\theta_{h}-\theta_{\ell}\right)<e_{h}^{o} \\
& \tau_{\ell}^{o}=-\frac{n_{h}}{n}\left(\theta_{h}-\theta_{\ell}\right)<0<\frac{n_{\ell}}{n}\left(\theta_{h}-\theta_{\ell}\right)=\tau_{h}^{o}, \quad t+\tau_{\ell}^{o}-\theta_{\ell}=t+\tau_{h}^{o}-\theta_{h}, \\
& u_{\ell}^{o}=u_{h}^{o}
\end{aligned}
$$

Proposition 1 states that, in the full information optimum, both types of jurisdictions consume the same quantities of the two public goods. High-cost jurisdictions incur higher cost for good $G$ than low-cost jurisdictions. Since regions face different fixed cost in producing good $G$, the federal government redistributes tax revenues from low-cost to high-cost regions $\left(\tau_{\ell}^{o}<0<\tau_{h}^{o}\right)$ such that 'net revenues' $t+\tau-\theta$ are equalized across regions. Hence, under full information, the optimal redistribution program completely offsets the cost disadvantage of high-cost regions such that these regions obtain the same utility level as low-cost ones.

For further use, it is helpful to illustrate the first-best optimum in the $(\tau, e)$-space. In this space, the indifference curve of a region are determined by $u=U(t+\tau-e)+V(e-\theta)$ where the region's index $i$ has been suppressed. Totally differentiating yields

$$
\begin{aligned}
& \left.\frac{d \tau}{d e}\right|_{d u=0}=\frac{U^{\prime}(t+\tau-e)-V^{\prime}(e-\theta)}{U^{\prime}(t+\tau-e)} \gtreqless 0 \quad \Leftrightarrow \quad \frac{U^{\prime}(t+\tau-e)}{V^{\prime}(e-\theta)} \gtreqless 1, \\
& \left.\frac{d^{2} \tau}{d e^{2}}\right|_{d u=0}=-\frac{V^{\prime 2} U^{\prime \prime}+U^{\prime 2} V^{\prime \prime}}{U^{\prime 3}}>0 .
\end{aligned}
$$

Hence, the indifference curves are U-shaped, and the minimum is at the point where the marginal rate of substitution between $\operatorname{good} F$ and $\operatorname{good} G$ is equal to unity. To the left (right) of the minimum, good $G$ is underprovided (overprovided) relative to good $F$, since $U^{\prime}(\cdot) / V^{\prime}(\cdot)<(>) 1$. If we move upwards in the $(\tau, e)$-space, then the region attains a higher utility level, since for given cost of good $G$ an increase in the transfer enhances the quantity of good $F$. Differentiating (8) with respect to $\theta$ one obtains

$$
\frac{d}{d \theta}\left(\left.\frac{d \tau}{d e}\right|_{d u=0}\right)=\frac{V^{\prime \prime}}{U^{\prime}}<0 .
$$


Consequently, at any given point in the $(\tau, e)$-space the slope of an indifference curve of a low-cost jurisdiction is larger than that of a high-cost jurisdiction. It follows that the indifference curves satisfy the single-crossing property.

Using this information about the indifference curves, Figure 1 illustrates the firstbest optimum characterized in proposition 1 .

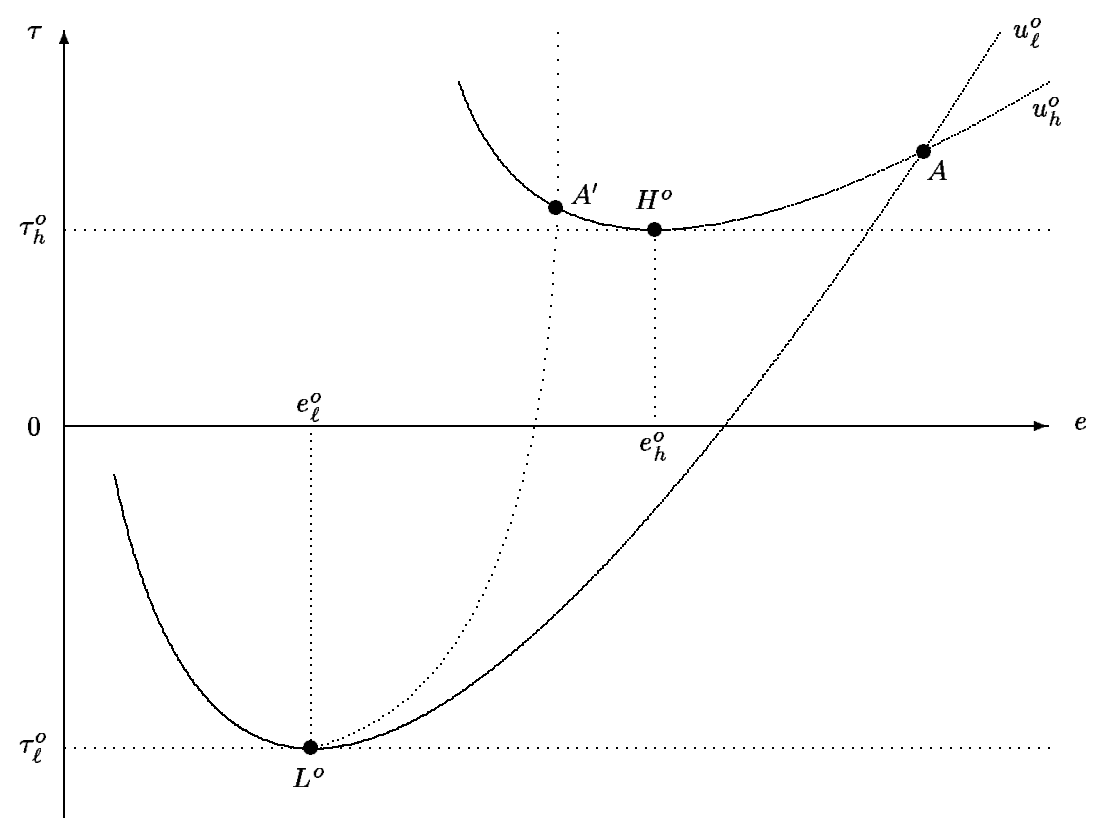

Figure 1: Full Information Optimum

The first-best optimum for low-cost and high-cost regions is represented by the points $L^{o}$ and $H^{o}$, respectively, since the indifference curves $u_{\ell}^{o}$ and $u_{h}^{o}$ attain their minimum at these points. For the subsequent analysis it is helpful to note that the indifference curves unambiguously intersect at a point like $A$ which lies to the right of point $H^{o}$. To understand this, notice first from proposition 1 that point $L^{o}$ must lie to the southwest of point $H^{o}$. The indifference curves cannot cross at a point to the left of $L^{o}$, because this would violate property (10). Furthermore, from the perspective of a lowcost region, point $H^{o}$ dominates point $L^{o}$ in terms of utility, since $f_{\ell}^{o}=f_{h}^{o}$ and $e_{\ell}^{o}<e_{h}^{o}$ imply $u_{\ell}^{o}=U\left(f_{\ell}^{o}\right)+V\left(e_{\ell}^{o}-\theta_{\ell}\right)<U\left(f_{h}^{o}\right)+V\left(e_{h}^{o}-\theta_{\ell}\right)$. It follows that the intersection of the indifference curves cannot lie at a point like $A^{\prime}$ to the left of $H^{o}$, but must be located on the increasing parts of both indifference curves, for instance, at point $A$.

So far, we have assumed that the federal government completely determines the 
entire allocation, i.e. there is full centralization of all decisions at the federal level. It is straightforward to check that this allocation can be decentralized by a system of lump-sum transfers: Suppose the federal government imposes a lump-sum tax $\tau_{\ell}^{o}$ on low-cost regions and uses the proceeds of this tax to pay an unconditional block grant $\tau_{h}^{o}$ to each high-cost region. Given the transfers, each jurisdiction decides on how to spend its funds on the goods $F$ and $G$ in order to maximize utility. The FOCs of utility maximization read $U^{\prime}\left(t+\tau_{i}^{o}-e_{i}\right)=V^{\prime}\left(e_{i}-\theta_{i}\right), i \in\{\ell, h\}$. These conditions are exactly the same as the efficiency conditions (6). Since transfers are set equal to their first-best levels, it follows that the optimal spending decisions of regions are $f_{i}=f_{i}^{o}$ and $g_{i}=g_{i}^{o}$ for $i \in\{\ell, h\}$. Hence, under full information the optimal allocation can be implemented simply by a transfer policy consisting of a lump-sum tax levied on low-cost regions and an unconditional block grant paid to high-cost regions. Such a program is feasible, since the federal government is able to verify the type of a jurisdiction. It follows that neither categorical block grants nor closed-ended matching grants are required to implement the first-best allocation.

\section{Asymmetric Information}

In this section, we turn to the case of asymmetric information. The following information structure is considered. Each jurisdiction $i$ knows as private information its cost parameter $\theta_{i}$ and the quantities of public goods, $f_{i}$ and $g_{i}$. The federal government can only observe the cost of public goods, $f_{i}$ and $e_{i}$. However, it cannot directly verify a jurisdiction's cost parameter $\theta_{i}$ and the quantity of good $G, g_{i}$. Intuitively, this assumption captures the idea that the federal government can observe total expenditures on good $G$, but cannot infer whether these expenditures reflect a high quantity or high fixed cost. As already mentioned in the introduction, our information structure differs from the one considered in Cornes and Silva (2003) who assume that the center can verify only total expenditures of a jurisdiction, i.e. $z_{i}:=f_{i}+e_{i}$, but cannot infer whether these expenditures result from providing good $G$ or good $F$.

Under asymmetric information, the first-best optimum of section 3 can no longer be attained. From figure 1, one can see that low-cost jurisdictions have an incentive to mimic high-cost jurisdictions since, by doing so, a low-cost jurisdiction realizes point $H^{o}$ 
instead of point $L^{o}$ with the consequence that it receives a transfer (instead of paying a transfer) and is able to increase its welfare by greater public consumption. The federal government cannot prevent this mimicking behavior, since it can no longer directly distinguish between high-cost and low-cost regions. The full information optimum $\left(L^{o}, H^{o}\right)$ is therefore not incentive compatible under asymmetric information. ${ }^{3}$

The second-best optimum can be derived as a standard asymmetric information problem. The federal government again solves the welfare maximization problem (5), but now additionally takes into account incentive compatibility constraints. ${ }^{4}$ The incentive compatibility constraint for low-cost regions reads

$$
U\left(t+\tau_{\ell}-e_{\ell}\right)+V\left(e_{\ell}-\theta_{\ell}\right) \geq U\left(t+\tau_{h}-e_{h}\right)+V\left(e_{h}-\theta_{\ell}\right)
$$

Thus, a low-cost jurisdiction's utility derived from its own transfer-spending scheme $\left(\tau_{\ell}, e_{\ell}\right)$ has to be at least as high as the utility from mimicking a high-cost jurisdiction, i.e. truth-telling weakly dominates lying. The analogous incentive compatibility constraint for high-cost jurisdictions is expressed by

$$
U\left(t+\tau_{h}-e_{h}\right)+V\left(e_{h}-\theta_{h}\right) \geq U\left(t+\tau_{\ell}-e_{\ell}\right)+V\left(e_{\ell}-\theta_{h}\right) .
$$

It will later be shown that, at the second-best optimum, constraint (12) holds as strict inequality. We therefore ignore this incentive compatibility constraint when deriving the second-best allocation.

The FOCs of the welfare maximization (5) under the additional constraint (11) are:

$$
\begin{array}{ll}
\underline{e_{\ell}}: & n_{\ell}\left[-U^{\prime}\left(f_{\ell}^{*}\right)+V^{\prime}\left(g_{\ell}^{*}\right)\right]+\mu\left[-U^{\prime}\left(f_{\ell}^{*}\right)+V^{\prime}\left(g_{\ell}^{*}\right)\right]=0, \\
\underline{e_{h}}: & n_{h}\left[-U^{\prime}\left(f_{h}^{*}\right)+V^{\prime}\left(g_{h}^{*}\right)\right]-\mu\left[-U^{\prime}\left(f_{h}^{*}\right)+V^{\prime}\left(e_{h}^{*}-\theta_{\ell}\right)\right]=0, \\
\underline{\tau_{\ell}}: & n_{\ell} U^{\prime}\left(f_{\ell}^{*}\right)-\lambda n_{\ell}+\mu U^{\prime}\left(f_{\ell}^{*}\right)=0, \\
\underline{\tau_{h}}: & n_{h} U^{\prime}\left(f_{h}^{*}\right)-\lambda n_{h}-\mu U^{\prime}\left(f_{h}^{*}\right)=0 .
\end{array}
$$

\footnotetext{
${ }^{3}$ If we model cost differences between jurisdictions as differences in unit cost instead of differences in fixed cost, then it is straightforward to show that the first-best optimum may or may not be incentive compatible. But our subsequent results on intergovernmental grants can be derived in such a framework, too, if we concentrate on the case where the first-best is not incentive compatible.

${ }^{4} \mathrm{As}$ in much of the literature on asymmetric information in federations, we do not explicitly take into account participation constraints. Intuitively, this can be motivated by the fact that the cost of leaving a federation are extremely high for a region.
} 
The star indicates second-best values. $\lambda$ and $\mu$ are Lagrange multipliers associated with the center's budget constraint (4) and the incentive compatibility constraint (11), respectively. Since the first-best allocation is no longer feasible, the incentive compatibility constraint (11) has to be binding at the second-best optimum. Formally, this is expressed by the fact that the FOCs (13) to (16) imply $\mu>0$, since otherwise $(\mu=0)$ they are equivalent to the FOCs (6) and (7) of the first-best optimum which is not incentive compatible, i.e. which violates the incentive compatibility constraint (11).

From the FOCs (13) we obtain

$$
\frac{U^{\prime}\left(f_{\ell}^{*}\right)}{V^{\prime}\left(g_{\ell}^{*}\right)}=1
$$

(17) is a variant of the standard 'no-distortion-at-the-top' result originally derived in the literature on optimal taxation under asymmetric information. In our framework, this result means that public goods spending of low-cost jurisdictions is not distorted in the second-best optimum, i.e. in low-cost regions the marginal rate of substitution between both public goods is still equal to unity. In contrast, the federal government has to distort public goods spending of high-cost jurisdictions: From (14) we obtain

$$
\left(n_{h}-\mu\right) U^{\prime}\left(f_{h}^{*}\right)=n_{h} V^{\prime}\left(g_{h}^{*}\right)-\mu V^{\prime}\left(e_{h}^{*}-\theta_{\ell}\right)>\left(n_{h}-\mu\right) V^{\prime}\left(g_{h}^{*}\right)
$$

since $e_{h}^{*}-\theta_{\ell}>e_{h}^{*}-\theta_{h}=g_{h}^{*}$ and, thus, $V^{\prime}\left(e_{h}^{*}-\theta_{\ell}\right)<V^{\prime}\left(g_{h}^{*}\right)$. From (16) follows $\left(n_{h}-\mu\right) U^{\prime}\left(f_{h}^{*}\right)=\lambda n_{h}>0$ which yields $n_{h}-\mu>0$. Equation (18) then implies

$$
\frac{U^{\prime}\left(f_{h}^{*}\right)}{V^{\prime}\left(g_{h}^{*}\right)}>1 .
$$

Hence, in the second-best optimum the marginal rate of substitution between good $F$ and good $G$ in high-cost jurisdictions exceeds unity implying overprovision of good $G$ relative to $\operatorname{good} F$.

The second-best optimum is further characterized in the following proposition which we prove in appendix $B$.

Proposition 2 (a) The second-best allocation under asymmetric information satisfies

(i) $\quad g_{\ell}^{*}>g_{h}^{*}, \quad f_{\ell}^{*}>f_{h}^{*}, \quad e_{\ell}^{*}<e_{h}^{*}$,

(ii) $\quad \tau_{\ell}^{*}<0<\tau_{h}^{*}, \quad t+\tau_{\ell}^{*}-\theta_{\ell}>t+\tau_{h}^{*}-\theta_{h}$,

(iii) $\quad u_{\ell}^{*}>u_{h}^{*}$ 
(b) Relative to the full information optimum, the second-best allocation satisfies

$$
\begin{array}{ll}
\text { (i) } \quad & g_{\ell}^{*}>g_{\ell}^{o}, \quad f_{\ell}^{*}>f_{\ell}^{o}, \quad g_{h}^{*} \gtreqless g_{h}^{o}, \quad f_{h}^{*}<f_{h}^{o}, \quad e_{\ell}^{*}>e_{\ell}^{o}, \quad e_{h}^{*} \gtreqless e_{h}^{o}, \\
(\text { ii }) & \tau_{\ell}^{*}>\tau_{\ell}^{o}, \quad \tau_{h}^{*}<\tau_{h}^{o},
\end{array}
$$$$
\text { (iii) } \quad u_{\ell}^{*}>u_{\ell}^{o}, \quad u_{h}^{*}<u_{h}^{o} \text {. }
$$

Proposition 2 (a) states that, in the second-best optimum, low-cost jurisdictions still have to pay transfers which are used to finance grants assigned to high-cost jurisdictions. However, low-cost regions dispose of more (net) resources $t+\tau-\theta$ than high-cost regions and, consequently, consume more of both public goods and realize higher utility, although their expenditures on good $G$ are lower than those of high-cost regions. Proposition 2 (b) shows that, in the second-best optimum, low-cost jurisdictions pay and high-cost jurisdictions receive lower transfers than in the first-best optimum. Hence, public consumption and utility of low-cost regions is larger than in the first-best optimum while high-cost regions attain a lower utility level and consume less of good $F$ than under full information. However, consumption of good $G$ in high-cost jurisdiction may be higher than in the first best.

The results of proposition 2 are illustrated in Figure 2. In the second-best optimum,

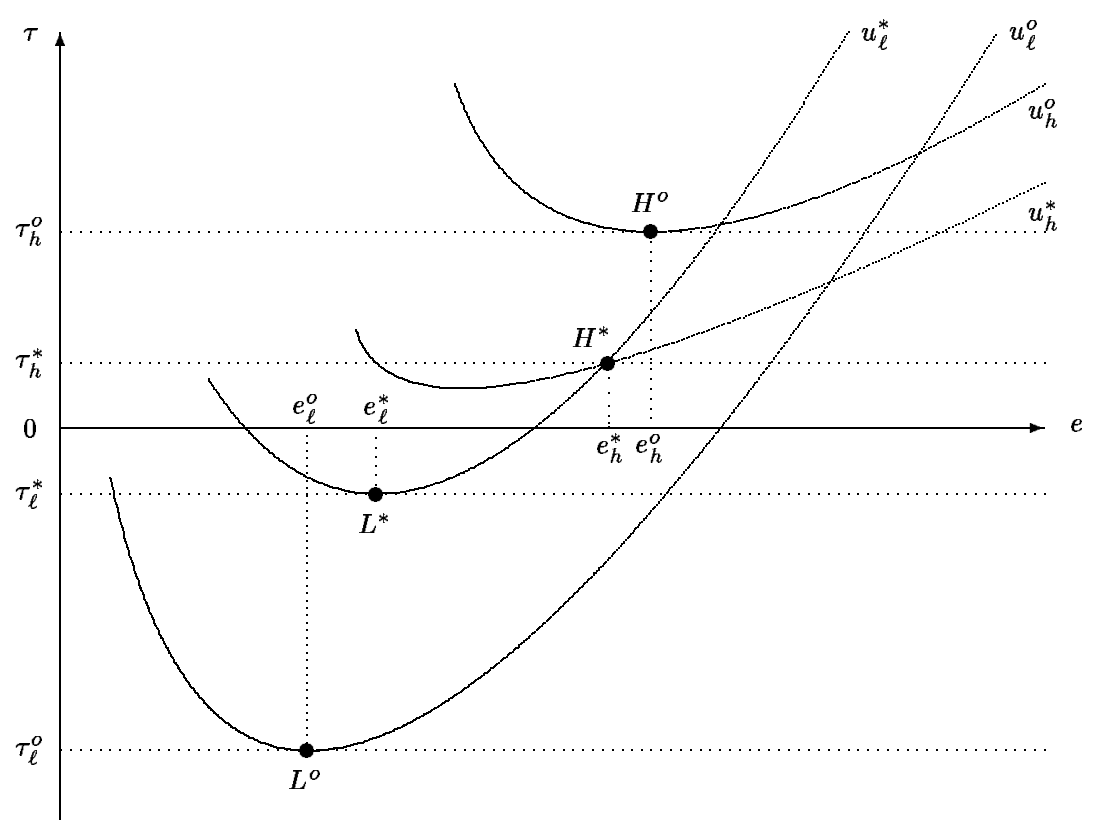

Figure 2: Asymmetric Information Optimum 
the federal government chooses the undistorted transfer-spending scheme $L^{*}$ for lowcost jurisdictions where these regions pay $\tau_{\ell}^{*}$ to the federal government and spend $e_{\ell}^{*}$ on good $G$. Any low-cost jurisdiction is indifferent between $L^{*}$ and the distorted scheme $H^{*}$ for high-cost jurisdictions where a transfer $\tau_{h}^{*}$ is paid by the federal government and spending of good $G$ amounts to $e_{h}^{*}$. The incentive compatibility of the second-best optimum $\left(L^{*}, H^{*}\right)$ is ensured by two properties. First, while the federal government still redistributes from low-cost to high-cost jurisdictions, a complete redistribution, i.e. a full equalization of utilities between jurisdictions, can no longer be attained. Relative to the first-best optimum $\left(L^{o}, H^{o}\right)$, utility of low-cost regions increases $\left(u_{\ell}^{*}>u_{\ell}^{o}\right)$ while utility of high-cost regions declines $\left(u_{h}^{*}<u_{h}^{o}\right)$. Asymmetric information therefore creates an information rent for low-cost regions. Second, the federal government distorts the spending of high-cost regions in favor of good $G$. By channelling funds into good $G$, the center benefits high-cost regions and tightens the incentive compatibility constraint for low-cost regions. Notice that the second-best optimum $\left(L^{*}, H^{*}\right)$ is also incentive compatible for high-cost regions, since their incentive compatibility constraint (12) is not binding at the optimum, i.e. they obtain more utility from $H^{*}$ than from $L^{*}$.

\section{Implementing the Second-Best Optimum}

In this section we analyze how the second-best optimum can be implemented in a decentralized economy. As in section 2, decentralization means that each jurisdiction decides on how to spend revenues on the two public goods while the federal government is responsible for the transfer policy. Since the first-best is no longer attainable under asymmetric information, the aim of the center's transfer policy is now to induce low-cost and high-cost regions to choose the second-best spending levels $\left(f_{\ell}^{*}, e_{\ell}^{*}\right)$ and $\left(f_{h}^{*}, e_{h}^{*}\right)$, respectively. The transfer policy is assumed to encompass two programs one of which is designed for low-cost jurisdictions (the $\ell$-program) while the other aims at highcost jurisdictions (the $h$-program). Because of the asymmetric information structure, a region can in fact choose one of the programs such that, in principle, a low-cost region may choose the $h$-program and a high-cost region may choose the $\ell$-program. The federal government therefore has to design its transfer policy such that the regions voluntarily choose the programs actually intended for them. 
We consider five transfer policies of the center summarized in Table 2. Under each

Table 2: Transfer Policies of the Federal Government

\begin{tabular}{|c|c|c|}
\hline $\begin{array}{c}\text { Transfer } \\
\text { Policy }\end{array}$ & $\ell$-Program & $h$-Program \\
\hline $\mathrm{P} 1$ & $\begin{array}{l}\text { Lump-sum tax: } \\
\qquad m_{\ell}=\tau_{\ell}^{*}<0\end{array}$ & Unconditional block grant: $m_{h}=\tau_{h}^{*}>0$ \\
\hline \multirow[t]{2}{*}{$\mathrm{P} 2 \mathrm{a}$} & $\begin{array}{l}\text { Lump-sum tax: } \\
\qquad m_{\ell}=\tau_{\ell}^{*}<0\end{array}$ & $\begin{array}{l}\text { 1.) Open-ended matching grant on good } G \text { : } \\
\alpha=1-V^{\prime}\left(e_{h}^{*}-\theta_{h}\right) / U^{\prime}\left(f_{h}^{*}\right)>0\end{array}$ \\
\hline & & 2.) Unconditional block grant: $m_{h}=\tau_{h}^{*}-\alpha e_{h}^{*}$ \\
\hline \multirow[t]{2}{*}{$\mathrm{P} 2 \mathrm{~b}$} & $\begin{array}{l}\text { Lump-sum tax: } \\
\qquad m_{\ell}=\tau_{\ell}^{*}<0\end{array}$ & $\begin{array}{l}\text { 1.) Open-ended matching grant on good } G \text { : } \\
\alpha=1-V^{\prime}\left(e_{h}^{*}-\theta_{\ell}\right) / U^{\prime}\left(f_{h}^{*}\right)>0\end{array}$ \\
\hline & & 2.) Unconditional block grant: $m_{h}=\tau_{h}^{*}-\alpha e_{h}^{*}$ \\
\hline \multirow[t]{2}{*}{ P3 } & Lump-sum tax: & 1.) Categorical block grant on $\operatorname{good} G: m_{G}=e_{h}^{*}>0$ \\
\hline & $m_{\ell}=\tau_{\ell}^{*}<0$ & 2.) Unconditional block grant: $m_{h}=\tau_{h}^{*}-e_{h}^{*}$ \\
\hline \multirow[t]{3}{*}{$\mathrm{P} 4$} & $\begin{array}{l}\text { Lump-sum tax: } \\
m_{\ell}=\tau_{\ell}^{*}<0\end{array}$ & $\begin{array}{l}\text { 1.) Closed-ended matching grant on good } G \text { : } \\
\alpha \in\left[1-V^{\prime}\left(e_{h}^{*}-\theta_{\ell}\right) / U^{\prime}\left(f_{h}^{*}\right), 1\right]\end{array}$ \\
\hline & & with ceiling: $z=\alpha e_{h}^{*}>0$ \\
\hline & & 2.) Unconditional block grant: $m_{h}=\tau_{h}^{*}-\alpha e_{h}^{*}$ \\
\hline
\end{tabular}

policy, the $\ell$-program is represented by a lump-sum tax $m_{\ell}$ which is set equal to the second-best value $\tau_{\ell}^{*}<0$. This program aims at low-cost jurisdictions which have to finance the redistribution necessary to obtain the second-best optimum. The transfer policies differ with respect to the $h$-program. This program is intended for high-cost regions and consists of alternative types of intergovernmental grants which will be described in more detail below.

Consider first policy P1. Under this policy, the $h$-program is represented by an unconditional block grant $m_{h}$ which equals the second-best transfer to high-cost regions, $\tau_{h}^{*}>0$. It is obvious that such a transfer policy does not implement the secondbest optimum: If a low-cost jurisdiction would choose the $\ell$-program, it would equate marginal utilities such that $U^{\prime}\left(t+\tau_{\ell}^{*}-e_{\ell}\right)=V^{\prime}\left(e_{\ell}-\theta_{\ell}\right)$ and, consequently, it would realize the undistorted second-best allocation $\left(f_{\ell}^{*}, e_{\ell}^{*}\right)$. But letting the block grant of 
the $h$-program be unconditional induces a low-cost region to mimic a high-cost one, since it then receives the $h$-program and attains higher utility according to $\tau_{h}^{*}>0>\tau_{\ell}^{*}$. Furthermore, a high-cost region choosing the $h$-program equates marginal utilities such that $U^{\prime}\left(t+\tau_{h}^{*}-e_{h}\right)=V^{\prime}\left(e_{h}-\theta_{h}\right)$. It therefore does not distort its spending decision as required for the second-best optimum. In sum, the transfer policy P1 cannot be used to decentralize the second-best optimum. This is a crucial difference to the decentralization of the first-best optimum, which in section 2 has been shown to be implementable with a lump-sum tax $\tau_{\ell}^{o}<0$ imposed on low-cost jurisdictions and an unconditional block grant $\tau_{h}^{o}>0$ assigned to high-cost jurisdictions.

For further use, Figure 3 illustrates the failure of transfer policy P1 in the $(f, e)$ space. Indifference curves in the $(f, e)$-space have negative slope and are convex. They

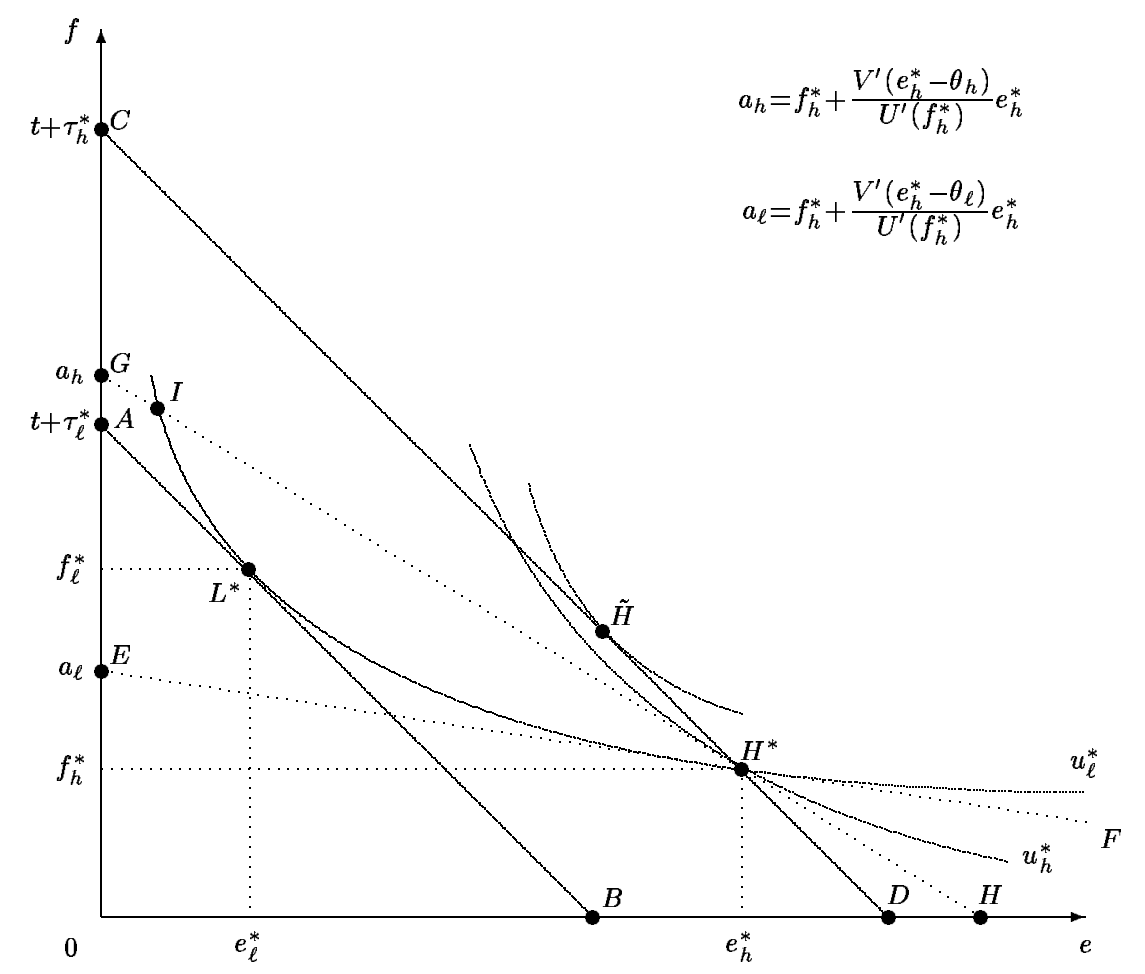

Figure 3: Implementing the Asymmetric Information Optimum

are steeper for high-cost than for low-cost jurisdictions. ${ }^{5}$ If a low-cost region chooses the $\ell$-program of transfer policy $\mathrm{P} 1$, then it faces the budget line $A B$ and realizes

\footnotetext{
${ }^{5}$ Totally differentiating $u=U(f)+V(e-\theta)$ yields $d f /\left.d e\right|_{d u=0}=-V^{\prime} / U^{\prime}<0, d^{2} f /\left.d e^{2}\right|_{d u=0}=$ $-\left(U^{\prime 2} V^{\prime \prime}+V^{\prime 2} U^{\prime \prime}\right) / U^{\prime 3}>0$ and $d\left(d f /\left.d e\right|_{d u=0}\right) / d \theta=V^{\prime \prime} / U^{\prime}<0$.
} 
the second-best allocation $L^{*}$ with utility $u_{\ell}^{*}$. But it has an incentive to deviate from this allocation, since it obtains higher utility under the $h$-program with the budget line $C D$. Furthermore, a high-cost jurisdiction chooses the $h$-program and realizes the undistorted allocation $\tilde{H}$. But the second-best optimum for high-cost regions is represented by the distorted allocation $H^{*}$ where the indifference curve $u_{\ell}^{*}$ of low-cost regions intersects the budget line $C D$ and where the high-cost regions' utility is $u_{h}^{*}$.

Consider now the transfer policies P2a and P2b. Under both policies, the $h$-program comprises an open-ended matching grant which subsidizes the spending on good $G$ at rate $\alpha$ and an unconditional block grant $m_{h}$ which, relative to the transfer policy P1, is reduced by the amount the region already receives by the matching grant. ${ }^{6}$ Under transfer policy P2a, the matching grant is such that high-cost regions voluntarily distort their spending decision in a second-best way: The budget line of a high-cost region under the $h$-program reads $f_{h}+(1-\alpha) e_{h}=t+m_{h}$ and is represented by the line $H G$ in Figure 3. This budget line is tangent to the indifference curve $u_{h}^{*}$ and, consequently, high-cost jurisdictions choose the second-best allocation $\left(f_{h}^{*}, e_{h}^{*}\right){ }^{7}$ Nevertheless, P2a is not suitable to implement the second-best optimum, since low-cost jurisdictions also choose the $h$-program which yields them higher utility on the segment $I H^{*}$ than at the point $L^{*}$ under the $\ell$-program. Transfer policy P2b slightly differs from P2a. The rate $\alpha$ of the matching grant under the $h$-program is now such that the budget line $E F$ is tangent to the indifference curve $u_{\ell}^{*}$. Thus, low-cost regions do not have an incentive to mimic high-cost ones and, at the margin, they choose the second-best allocation $L^{*}$. Nonetheless, also the transfer policy P2b is not suitable to implement the second-best optimum, since high-cost jurisdictions maximize utility by choosing an undistorted allocation on the segment $H^{*} F$. In sum, open-ended matching grants, which are often proposed by economists for internalizing externalities between jurisdictions, cannot be used to implement the second-best optimum under asymmetric information.

\footnotetext{
${ }^{6}$ When the region's own revenues $t$ are relatively large, then $m_{h}=\tau_{h}^{*}-\alpha e_{h}^{*}=f_{h}^{*}+(1-\alpha) e_{h}^{*}-t$ is negative and represents a lump-sum tax. This is true also under the policies P3 and P4 which we discuss later. To ease exposition, however, we suppose throughout that $m_{h}$ represents a grant.

${ }^{7}$ Formally, a high-cost region maximizes $U\left[t+m_{h}-(1-\alpha) e_{h}\right]+V\left(e_{h}-\theta_{h}\right)$ taking as given $\alpha$ and $m_{h}$. The FOC can be written as $U^{\prime}\left[f_{h}^{*}+\left(e_{h}^{*}-e_{h}\right) \cdot V^{\prime}\left(e_{h}^{*}-\theta_{h}\right) / U^{\prime}\left(f_{h}^{*}\right)\right] / V^{\prime}\left(e_{h}-\theta_{h}\right)=U^{\prime}\left(f_{h}^{*}\right) / V^{\prime}\left(e_{h}^{*}-\theta_{h}\right)$. Due to the concavity of the utility function, the only solution to this FOC is $e_{h}=e_{h}^{*}$ implying $f_{h}=f_{h}^{*}$.
} 
Under the transfer policy $\mathrm{P} 3$, a region choosing the $h$-program receives a categorical block grant $m_{G}$ which has to be spend on good $G$ and which equals the second-best spending on this good. In addition, the region receives an unconditional block grant $m_{h}$ which represents that part of the second-best transfer to high-cost regions which is not yet disbursed by the categorical block grant. This $h$-program is similar to the one under transfer policy P1. The key difference is that it requires the region to spend at least $e_{h}^{*}$ of its received grants on good $G$. The corresponding budget constraint is therefore represented by the line $H^{*} D$ in Figure 3. Clearly, such a transfer policy ensures incentive compatibility for low-cost jurisdictions, since they are indifferent between the $\ell$-program with maximum utility at $L^{*}$ and the $h$-program with maximum utility at $H^{*}$. Moreover, the transfer policy P3 also distorts the allocation for high-cost regions, since they choose the $h$-program with maximum utility at $H^{*}$. In sum, a combination of unconditional and categorical block grants can decentralize the second-best optimum under asymmetric information.

Consider finally the transfer policy $\mathrm{P} 4$. Under this policy, the $h$-program combines the unconditional block grant $m_{h}$ with a closed-ended matching grant. The matching grant covers the share $\alpha$ of the expenditures on $\operatorname{good} G$ where $\alpha$ has to be at least as high as under the transfer policy P2b. ${ }^{8}$ But the federal government pays this matching grant only up to the maximum amount $z=\alpha e_{h}^{*}$. If a jurisdiction chooses the $h$-program and spends more than $e_{h}^{*}$ on $\operatorname{good} G$, then the additional spending has to be fully borne by the jurisdiction itself. More formally, under the $h$-program the budget constraint of a type $i$ region can be written as

$$
f_{i}+e_{i}=\left\{\begin{array}{llll}
t+m_{h}+\alpha e_{i}, & \text { if } \alpha e_{i} \leq z & \text { or, equivalently, } & e_{i} \leq e_{h}^{*} \\
t+m_{h}+z, & \text { if } \alpha e_{i}>z & \text { or, equivalently, } & e_{i}>e_{h}^{*}
\end{array}\right.
$$

If $\alpha$ is equal to $1-V^{\prime}\left(e_{h}^{*}-\theta_{\ell}\right) / U^{\prime}\left(f_{h}^{*}\right)$ (its lowest possible value under policy $\mathrm{P} 4$ ), then the budget constraint (20) is represented by the line $E H^{*} D$ in Figure 3: Along the segment $E H^{*}$, the region benefits from the matching grant $\alpha$ on good $G$. The segment $H^{*} D$ reflects that the matching grant is closed-ended. Since the segment $E H^{*}$ is tangent to the indifference curve $u_{\ell}^{*}$ at the point $H^{*}$, it is obvious that the transfer policy P4 (i) is

\footnotetext{
${ }^{8}$ Notice that for $\alpha=1$ we obtain the categorical block grant of policy P3 as a limiting case of a closed-ended matching grant.
} 
incentive compatible for low-cost regions (which are indifferent between the $\ell$-program with maximum utility at $L^{*}$ and the $h$-program with maximum utility at $H^{*}$ ) and (ii) distorts the spending decision of high-cost jurisdictions (which choose the $h$-program with maximum utility at $H^{*}$ ). Hence, the transfer policy P4 is suitable to decentralize the second-best optimum. Notice that there are many combinations of closed-ended matching grants and unconditional block grants which satisfy the conditions (i) and (ii): If the federal government raises the subsidy rate $\alpha$ beyond its lowest value $1-$ $V^{\prime}\left(e_{h}^{*}-\theta_{\ell}\right) / U^{\prime}\left(f_{h}^{*}\right)$, the ceiling $z=\alpha e_{h}^{*}$ also increases while the unconditional block grant $m_{h}=\tau_{h}^{*}-\alpha e_{h}^{*}$ decreases. This makes the segment $E H^{*}$ of the budget constraint under the $h$-program flatter, but incentive compatibility for low-cost regions and the spending distortion of high-cost regions is maintained.

The results of our discussion in this section are summarized in

Proposition 3 The second-best optimum under asymmetric information can be decentralized by the transfer policies $\mathrm{P}_{3}$ and $\mathrm{P} 4$ but not by P1, P2a and P2b.

Hence, the second-best optimum can be implemented in a decentralized economy if a part of the transfer to high-cost jurisdictions is paid either as categorical block grant or as closed-ended matching grant. The rationale for this result is that both types of grants (i) distort the spending decision of high-cost jurisdictions in a second-best way and (ii) are sufficiently unattractive for low-cost jurisdictions such that they voluntarily decide to pay the lump-sum tax actually intended for them. If the federal government employs pure unconditional block grants or open-ended matching grants, then either condition (i) or condition (ii) is violated.

\section{Conclusions}

This paper considered a federal government which redistributes resources between regions. Regions provide two types of public goods and differ with respect to the cost of these goods. It has been shown that the optimal redistribution program is characterized by full equalization of welfare between regions, if the federal government can perfectly observe the regions' cost conditions. In a decentralized economy, this first-best optimum can be implemented by lump-sum taxes and transfers. However, 
we have also shown that the first-best optimum is not feasible in case of asymmetric information in which the center cannot directly distinguish between low-cost and high-cost regions. Optimal redistribution is then second-best and characterized by a distortion of the spending decision of high-cost jurisdictions and a binding incentive compatibility constraint for low-cost regions. This second-best optimum can be decentralized with the help of categorical block grants or closed-ended matching grants. In contrast, unconditional block grants and open-ended matching grants are not suitable to implement the second-best allocation.

Hence, our analysis provides a theoretical explanation for the widely use of categorical block grants and closed-ended matching grants in many federations. The next step is to put this theory into action. For example, Inman (1988) found that only a part of the U.S. system of federal grants to state and local governments can be explained by the standard efficiency and equity arguments provided by the fiscal federalism literature. We hope that our theory can in part resolve this empirical puzzle and makes a further contribution to the explanation of real world grants system. Proving this requires some econometric work which is beyond the scope of the present paper. But we hope that our analysis stimulates such empirical research on federal grants system.

\section{Appendix}

\section{A. Proof of Proposition 1}

(7) immediately implies $g_{\ell}^{o}=g_{h}^{o}$. This together with (6) yields $f_{\ell}^{o}=f_{h}^{o}$. Together with

(1) we obtain $e_{\ell}^{o}=e_{h}^{o}-\left(\theta_{h}-\theta_{\ell}\right)<e_{h}^{o}$ which completes the proof of (i). From $f_{\ell}^{o}=f_{h}^{o}$,

(2) and $e_{\ell}^{o}=e_{h}^{o}-\left(\theta_{h}-\theta_{\ell}\right)$ follows $\tau_{\ell}^{o}-\theta_{\ell}=\tau_{h}^{o}-\theta_{h}$. Solving this with respect to $\tau_{\ell}^{o}$ and inserting the resulting expression into (4) yields $\tau_{\ell}^{o}=-n_{h}\left(\theta_{h}-\theta_{\ell}\right) / n<0$ and $\tau_{h}^{o}=n_{\ell}\left(\theta_{h}-\theta_{\ell}\right) / n>0$ which completes the proof of (ii). Part (iii) follows from (i).

\section{B. Proof of Proposition 2}

Consider first proposition 2 (a). Equations (15) and (16) can be rearranged to yield

$$
\frac{n_{\ell}+\mu}{n_{\ell}} U^{\prime}\left(f_{\ell}^{*}\right)=\lambda=\frac{n_{h}-\mu}{n_{h}} U^{\prime}\left(f_{h}^{*}\right)
$$


From $\left(n_{\ell}+\mu\right) / n_{\ell}>\left(n_{h}-\mu\right) / n_{h}$ follows $U^{\prime}\left(f_{\ell}^{*}\right)<U^{\prime}\left(f_{h}^{*}\right)$ and, thus, $f_{\ell}^{*}>f_{h}^{*}$. (13) and (14) imply $U^{\prime}\left(f_{\ell}^{*}\right)=V^{\prime}\left(g_{\ell}^{*}\right)$ and $\left(n_{h}-\mu\right) U^{\prime}\left(f_{h}^{*}\right)=n_{h} V^{\prime}\left(g_{h}^{*}\right)-\mu V^{\prime}\left(e_{h}^{*}-\theta_{\ell}\right)$. Using these expressions in (21), we obtain

$$
V^{\prime}\left(g_{\ell}^{*}\right)-V^{\prime}\left(g_{h}^{*}\right)=-\mu\left[\frac{V^{\prime}\left(g_{\ell}^{*}\right)}{n_{\ell}}+\frac{V^{\prime}\left(e_{h}^{*}-\theta_{\ell}\right)}{n_{h}}\right]<0
$$

and hence $g_{\ell}^{*}>g_{h}^{*}$. Since the incentive compatibility constraint (11) is binding at the second-best optimum, it can be written as $U\left(f_{\ell}^{*}\right)+V\left(e_{\ell}^{*}-\theta_{\ell}\right)=U\left(f_{h}^{*}\right)+V\left(e_{h}^{*}-\theta_{\ell}\right)$. From $f_{\ell}^{*}>f_{h}^{*}$ we obtain $U\left(f_{\ell}^{*}\right)>U\left(f_{h}^{*}\right)$ and, hence, $V\left(e_{\ell}^{*}-\theta_{\ell}\right)<V\left(e_{h}^{*}-\theta_{\ell}\right)$. It follows that $e_{\ell}^{*}<e_{h}^{*}$ which completes the proof of part (i).

According to (17), the second-best allocation for low-cost regions is at the minimum of a low-cost region's indifference curve. The second-best allocation for high-cost regions lies on the same indifference curve, since the incentive compatibility constraint (11) is binding. The U-shape of the indifference curves therefore implies $\tau_{\ell}^{*}<0<\tau_{h}^{*}$. $f_{\ell}^{*}>f_{h}^{*}$ and $g_{\ell}^{*}>g_{h}^{*}$ together with (1) and (2) yield $t+\tau_{\ell}^{*}-\theta_{\ell}>t+\tau_{h}^{*}-\theta_{h}$ which completes the proof of part (ii). Part (iii) follows directly from part (i).

Next turn to the proof of proposition 2 (b) and let us start with part (ii). From proposition 2 (a) (ii) it follows that $\tau_{\ell}^{*}>\tau_{h}^{*}-\left(\theta_{h}-\theta_{\ell}\right)$. Inserting this expression into the budget constraint of the federal government (4) and rearranging yields $\tau_{h}^{*}<n_{\ell}\left(\theta_{h}-\right.$ $\left.\theta_{\ell}\right) / n=\tau_{h}^{o} . \tau_{\ell}^{*}>\tau_{\ell}^{o}$ can be proven by contradiction: $\tau_{\ell}^{*} \leq \tau_{\ell}^{o}$ implies $n_{\ell} \tau_{\ell}^{*}+n_{h} \tau_{h}^{*}<$ $n_{\ell} \tau_{\ell}^{o}+n_{h} \tau_{h}^{o}=t$ which violates the budget constraint of the federal government.

To demonstrate (i) of proposition (b), imagine the first-best and second-best allocations in the $(f, g)$-space. According to $\tau_{\ell}^{*}>\tau_{\ell}^{o}$, in the second-best optimum low-cost jurisdictions dispose of a higher 'income' $t+\tau_{\ell}$ than in the first-best optimum. Moreover, (17) implies that their public goods spending is not distorted, i.e. their optimum is reached where the budget constraint is tangent to the indifference curve. Since we have assumed additively separable preference, both public goods are normal and it follows $f_{\ell}^{*}>f_{\ell}^{o}$ and $g_{\ell}^{*}>g_{\ell}^{o}$ which, in turn, implies $e_{\ell}^{*}>e_{\ell}^{o}$ according to (1).

With respect to high-cost jurisdictions suppose, for the time being, that their public goods spending in the second-best optimum is not distorted, and let $\tilde{f}_{h}$ and $\tilde{g}_{h}$ be the respective quantities of public goods. By the same arguments as for low-cost jurisdictions, we then obtain $\tilde{f}_{h}<f_{h}^{o}$ and $\tilde{g}_{h}<g_{h}^{o}$, since income $t+\tau_{h}$ is smaller than in the first-best optimum according to $\tau_{h}^{*}<\tau_{h}^{o}$. But from (19) it is known that the 
spending decision of high-cost jurisdictions is distorted in the second-best optimum such that overprovision of good $G$ occurs (graphically, in the $(f, g)$-space the indifference curve crosses the budget constraint from below). With respect to good $F$, we therefore unambiguously obtain $f_{h}^{*}<\tilde{f}_{h}<f_{h}^{o}$. But with respect to good $G$, it cannot be excluded that $g_{h}^{*}>\tilde{g}_{h}<g_{h}^{o}$. In general, we thus obtain $g_{h}^{*} \gtreqless g_{h}^{o}$ and $e_{h}^{*} \gtreqless e_{h}^{o}$ which completes the proof of part (i). Finally, part (iii) follows directly from part (ii).

\section{References}

Baker, M., Payne, A.A. and M. Smart (1999), 'An Empirical Study of Matching Grants: The 'Cap on CAP", Journal of Public Economics 72, 269-288.

Bezdek, R. and J.D. Jonathan (1988), 'Federal Categorical Grants-in-Aid and State Local Government Expenditures', Public Finance/Finances Publiques 43, 39-55.

Bordignon, M., Manasse, P. and G. Tabellini (2001), 'Optimal Regional Redistribution under Asymmetric Information', American Economic Review 91, 709-723.

Bucovetsky, S., Marchand, M. and P. Pestieu (1998), 'Tax Competition and Revelation of Preferences for Public Expenditures', Journal of Urban Economics 44, 367390.

Cornes, R.C. and E.C.D. Silva (2000), 'Local Public Goods, Risk Sharing and Private Information in Federal Systems', Journal of Urban Economics 47, 39-60.

Cornes, R.C. and E.C.D. Silva (2002), 'Local Public Goods, Interregional Transfers and Private Information', European Economic Review 46, 329-356.

Cornes, R.C. and E.C.D. Silva (2003), 'Public Good Mix in a Federation with Incomplete Information', Journal of Public Economic Theory, forthcoming.

Cremer, H., Marchand, M. and P. Pestieu (1996), 'International Redistribution through Tax Surcharge', International Tax and Public Finance 3, 157-73.

Deaton, A. and J. Muellbauer (1980), Economics and Consumer Behaviour, Cambridge: Cambridge University Press. 
Hevré, Y. (2002), Intergovernmental Transfers as a Macroeconomic Success Story of the European Integration: Myth or Reality?, Baden-Baden: Nomos Verlagsgesellschaft.

Huber, B., Baretti, C. and K. Lichtblau (2002), 'A Tax on Tax Revenue - The Incentive Effects of Equalizing Transfers: Evidence from Germany', International Tax and Public Finance 9, 631-649.

Inman R. (1988), 'Federal Assistance and Local Services in the United States: The Evolution of a New Federalist Fiscal Order', in: Rosen, H. (Eds.), Fiscal Federalism: Quantitative Studies, Chicago: University of Chicago Press, 33-77.

Lockwood, B. (1999), 'Inter-regional Insurance', Journal of Public Economics 72, $1-37$.

Oates, W.E. (1972), Fiscal Federalism, New York: Harcourt, Brace, Jovanovich.

Oates, W.E. (1999), 'An Essay on Fiscal Federalism', Journal of Economic Literature 37, 1120-1149.

U.S. General Accounting Office (1996), Federal Grants: Design Improvements Could Help Federal Resources Go Further, Washington.

Wildasin, D. (1985), Urban Public Finance, New York: Harwood. 


\title{
CESifo Working Paper Series
}

\author{
(for full list see www.cesifo.de)
}

852 Gregory D. Hess, The Economic Welfare Cost of Conflict: An Empirical Assessment, February 2003

853 Douglas J. Cumming and Jeffrey G. MacIntosh, Comparative Venture Capital Governance. Private versus Labour Sponsored Venture Capital Funds, February 2003

854 Eckhard Janeba and John Douglas Wilson, Decentralization and International Tax Competition, February 2003

855 Tapio Palokangas, Capital Accumulation and Employment Cycles in a Model of Creative Destruction, February 2003

856 Brendan Walsh, When Unemployment Disappears: Ireland in the 1990s, February 2003

857 Luis H. R. Alvarez and Erkki Koskela, A General Approach to the Stochastic Rotation Problem with Amenity Valuation, February 2003

858 Christian Schultz, Strategic Campaigns and Redistributive Politics, February 2003

859 Ernst Fehr and Joseph Henrich, Is Strong Reciprocity a Maladaptation? On the Evolutionary Foundations of Human Altruism, February 2003

860 Haizhou Huang, Dalia Marin, and Chenggang Xu, Financial Crisis, Economic Recovery and Banking Development in Former Soviet Union Economies, February 2003

861 Pedro Cardoso and Bernard M.S. van Praag, How Sustainable Are Old-age Pensions in a Shrinking Population with Endogenous Labour Supply?, February 2003

862 Volker Meier, Efficient Transfer of Aging Provisions in Private Health Insurance, February 2003

863 Edward Castronova, Theory of the Avatar, February 2003

864 Robert S. Chirinko, Hans van Ees, Harry Garretsen, and Elmer Sterken, Investor Protections and Concentrated Ownership: Assessing Corporate Control Mechanisms in the Netherlands, February 2003

865 Bernard M.S. van Praag and Pedro Cardoso, The Mix Between Pay-as-you-go and Funded Pensions and what Demography has to do with it, February 2003

866 Ernst Fehr, Urs Fischbacher, Bernhard von Rosenbladt, Jürgen Schupp, and Gert G. Wagner, A Nation-Wide Laboratory. Examining Trust and Trustworthiness by Integrating Behavioral Experiments into Representative Survey, February 2003 
867 Frank Heinemann, The Inflationary Impact of Wage Indexation, February 2003

868 Eytan Sheshinski, Bounded Rationality and Socially Optimal Limits on Choice in a Self-Selection Model, February 2003

869 M. Hashem Pesaran, Estimation and Inference in Large Heterogenous Panels with Cross Section Dependence, February 2003

870 Luis H. R. Alvarez and Erkki Koskela, On the Tree-Cutting Problem under Interest Rate and Forest Value Uncertainty, February 2003

871 Norbert Berthold and Rainer Fehn, Unemployment in Germany: Reasons and Remedies, February 2003

872 Clemens Fuest, Bernd Huber, and Philipp Tilleßen, Tax Policy and Entrepreneurship in the Presence of Asymmetric Information in Capital Markets, February 2003

873 Eytan Sheshinski, Optimum and Risk-Class Pricing of Annuities, February 2003

874 Willi Leibfritz, Paul O'Brien and Jean-Christophe Dumont, Effects of Immigration on Labour Markets and Government Budgets - An Overview, February 2003

875 M. Hashem Pesaran and Allan Timmermann, How Costly is it to Ignore Breaks when Forecasting the Direction of a Time Series?, February 2003

876 Thorvaldur Gylfason and Gylfi Zoega, Education, Social Equality and Economic Growth: A View of the Landscape, February 2003

877 Robin Boadway and Jean-François Tremblay, Public Economics and Startup Entrepreneurs, February 2003

878 Erkki Koskela and Roope Uusitalo, The Un-Intended Convergence: How the Finnish Unemployment Reached the European Level, February 2003

879 Robert Fenge and Volker Meier, Pensions and Fertility Incentives, February 2003

880 Eytan Sheshinski, Note on Income Taxation and Occupational Choice, February 2003

881 A B Atkinson, Income Inequality in OECD Countries: Data and Explanations, February 2003

882 Thomas Gehrig and Rune Stenbacka, Venture Cycles: Theory and Evidence, February 2003

883 Ralf Becker and Thomas Hellmann, The Genesis of Venture Capital - Lessons from the German Experience, March 2003

884 Eytan Sheshinski, Note on the Optimum Pricing of Annuities, March 2003

885 Paul De Grauwe and Magdalena Polan, Globalisation and Social Spending, March 2003 
886 F. van der Ploeg, Do Social Policies Harm Employment and Growth?, March 2003

887 Mirjam van Praag, Initial Capital Constraints Hinder Entrepreneurial Venture Performance: An empirical analysis, March 2003

888 Bernard Steunenberg, Coordinating Sectoral Policymaking: Searching for Countervailing Mechanisms in the EU Legislative Process, March 2003

889 Eytan Sheshinski, Optimum Delayed Retirement Credit, March 2003

890 Frederick van der Ploeg, Rolling Back the Public Sector - Differential effects on employment, investment and growth, March 2003

891 Paul De Grauwe and Marc-Alexandre Sénégas, Monetary Policy in EMU when the Transmission is Asymmetric and Uncertain, March 2003

892 Steffen Huck and Kai A. Konrad, Strategic Trade Policy and the Home Bias in Firm Ownership Structure, March 2003

893 Harry Flam, Turkey and the EU: Politics and Economics of Accession, March 2003

894 Mathias Hoffmann and Ronald MacDonald, A Re-examination of the Link between Real Exchange Rates and Real Interest Rate Differentials, March 2003

895 Badi H. Baltagi, Espen Bratberg, and Tor Helge Holmås, A Panel Data Study of Physicians' Labor Supply: The Case of Norway, March 2003

896 Dennis C. Mueller, Rights and Citizenship in the European Union, March 2003

897 Jeremy Edwards, Gains from Trade in Tax Revenue and the Efficiency Case for Trade Taxes, March 2003

898 Rainer Fehn and Thomas Fuchs, Capital Market Institutions and Venture Capital: Do They Affect Unemployment and Labour Demand?, March 2003

899 Ronald MacDonald and Cezary Wójcik, Catching Up: The Role of Demand, Supply and Regulated Price Effects on the Real Exchange Rates of Four Accession Countries, March 2003

900 R. Selten, M. Schreckenberg, T. Pitz, T. Chmura, and S. Kube, Experiments and Simulations on Day-to-Day Route Choice-Behaviour, April 2003

901 Stergios Skaperdas, Restraining the Genuine Homo Economicus: Why the Economy Cannot be Divorced from its Governance, April 2003

902 Yin-Wong Cheung, Menzie D. Chinn, and Antonio Garcia Pascual, What Do We Know about Recent Exchange Rate Models? In-Sample Fit and Out-of-Sample Performance Evaluated, April 2003

903 Mika Widgrén, Enlargements and the Principles of Designing EU - Decision-Making Procedures, April 2003 
904 Phornchanok Cumperayot, Dusting off the Perception of Risk and Returns in FOREX Markets, April 2003

905 Kai A Konrad, Inverse Campaigning, April 2003

906 Lars P. Feld and Stefan Voigt, Economic Growth and Judicial Independence: Cross Country Evidence Using a New Set of Indicators, April 2003

907 Giuseppe Bertola and Pietro Garibaldi, The Structure and History of Italian Unemployment, April 2003

908 Robert A.J. Dur and Otto H. Swank, Producing and Manipulating Information, April 2003

909 Christian Gollier, Collective Risk-Taking Decisions with Heterogeneous Beliefs, April 2003

910 Alexander F Wagner, Mathias Dufour, and Friedrich Schneider, Satisfaction not Guaranteed - Institutions and Satisfaction with Democracy in Western Europe, April 2003

911 Ngo Van Long, Raymond Riezman, and Antoine Soubeyran, Trade, Wage Gaps, and Specific Human Capital Accumulation, April 2003

912 Andrea Goldstein, Privatization in Italy 1993-2002: Goals, Institutions, Outcomes, and Outstanding Issues, April 2003

913 Rajshri Jayaraman and Mandar Oak, The Signaling Role of Municipal Currencies in Local Development, April 2003

914 Volker Grossmann, Managerial Job Assignment and Imperfect Competition in Asymmetric Equilibrium, April 2003

915 Christian Gollier and Richard Zeckhauser, Collective Investment Decision Making with Heterogeneous Time Preferences, April 2003

916 Thomas Moutos and William Scarth, Some Macroeconomic Consequences of Basic Income and Employment Subsidies, April 2003

917 Jan C. van Ours, Has the Dutch Miracle Come to an End?, April 2003

918 Bertil Holmlund, The Rise and Fall of Swedish Unemployment, April 2003

919 Bernd Huber and Marco Runkel, Optimal Design of Intergovernmental Grants under Asymmetric Information, April 2003 